\title{
A low-molecular-mass protein from Methylococcus capsulatus (Bath) is responsible for the regulation of formaldehyde dehydrogenase activity in vitro
}

\author{
Stephen Tate† and Howard Dalton
}

Department of Biological Sciences, University of Warwick, Coventry CV4 7AL, UK
Author for correspondence: Howard Dalton. Tel: +44 1203 523552. Fax: +44 1203523568. e-mail: hd@dna.bio.warwick.ac.uk

\begin{abstract}
An $8.6 \mathrm{kDa}$ protein, which the authors call a modifin, has been purified from Methylococcus capsulatus (Bath) and has been shown to alter the substrate specificity and kinetics of NAD+-linked formaldehyde dehydrogenase (FDH) isolated from the same organism. Purification methods for both the modifin and FDH are presented which reliably produced pure protein for further analysis. Analysis of the molecular mass and $\mathbf{N}$-terminal sequence of both FDH and the modifin indicate that they are unique proteins and show no similarity to alcohol or aldehyde dehydrogenase enzymes isolated from methylotrophic bacteria. Substrate specificity studies demonstrated that FDH oxidized formaldehyde exclusively in the presence of the modifin; a diverse range of aldehydes and alcohols were oxidized by FDH in the absence of the modifin. No formaldehyde oxidation was detected in the absence of the modifin. Attempts to replace the modifin with glutathione or high concentrations of methanol to stimulate formaldehyde oxidation failed. With acetaldehyde as substrate, FDH showed standard Michaelis-Menten kinetics; interaction of FDH with the modifin using formaldehyde as substrate altered the kinetics of the reaction to sigmoidal. Kinetic analysis during turnover experiments indicated that the FDH may be associated with bound formaldehyde following enzyme isolation and that NAD may also be associated with the enzyme but in a form that is less tightly bound than found with the methanol dehydrogenase from Bacillus methanolicus. Data are presented which indicate that the modifin may play an important role in regulating formaldehyde concentration in vivo.
\end{abstract}

Keywords: Methylococcus capsulatus (Bath), modifier protein, protein regulation, formaldehyde dehydrogenase

\section{INTRODUCTION}

Methylotrophic bacteria that grow on single-carbon compounds as their sole carbon and energy source produce formaldehyde as an intermediate from the oxidation of the primary carbon substrate (Anthony, 1982). Formaldehyde can then either be assimilated via one or more pathways into central metabolites or

†Present address: Delta Biotechnology Ltd, Castle Court, Castle Boulevard, Nottingham NG7 1FD, UK.

Abbreviations: $\mathrm{CV}$, column volume; ESI-MS, electrospray ionization mass spectrometry; FDH, formaldehyde dehydrogenase; gFDH, GSH-dependent formaldehyde dehydrogenase; HTSE, heat-treated soluble extract; $M D H$, methanol dehydrogenase; $S M M O$, soluble methane monooxygenase. oxidized further to carbon dioxide, generating energy in the form of $\mathrm{NADH}_{2}$. The oxidation of formaldehyde to formate is catalysed by formaldehyde dehydrogenase (FDH), of which there are two principal types depending on whether the electron acceptor is $\mathrm{NAD}^{+}$or an artificial dye. Within these two groups eight different forms have been identified (Stirling \& Dalton, 1978). These have been classified according to their requirements for secondary cofactors such as glutathione (Harrington \& Kallio, 1960; Hampton \& Zatman, 1973; Johnson \& Quayle, 1964; Eggeling \& Sahm, 1984; van Ophem et al., 1992), other thiol compounds (Poels \& Duine, 1989), other proteins (Stirling \& Dalton, 1978), or their need for an activator, such as tetrahydrofolate (Large \& Quayle, 1963). They have also been classified according 
to their substrate specificity (Johnson \& Quayle, 1964; Patel \& Hoare, 1971; Boulton \& Large, 1977).

The FDH enzyme isolated from Metbylococcus capsulatus (Bath) is particularly unusual in that it required a heat-stable $\left(70{ }^{\circ} \mathrm{C} / 12 \mathrm{~min}\right)$ dialysable protein for activity. No formaldehyde oxidation activity was detected if this heat-stable factor was replaced by thiol compounds (Stirling \& Dalton, 1978). Attempts to purify the heat-stable protein met with little success. Subsequent attempts to purify this component by J. Green in our laboratory (unpublished observations) led to the observation that the FDH component of the complex would only oxidize formaldehyde in the presence of the heat-stable protein. In the absence of the heat-stable protein FDH was able to oxidize other aldehydes and some alcohols.

This communication reports our findings concerning the interaction of the heat-stable modifier protein (which we prefer to call a modifin since it is able to modify the substrate specificity of the dehydrogenase) with FDH. In particular we describe reliable purification methodologies for both the modifin and FDH. Kinetic data are also presented on the interaction between the modifin and FDH which suggest how the alteration in the substrate specificity may be effected.

\section{METHODS}

All reagents, unless otherwise stated, were purchased from Sigma and were of the highest grade available. All spectrophotometric measurements were made using a Hewlett Packard HP8452A diode array spectrophotometer (Hewlett Packard).

Formaldehyde determination. The acetylacetone method for formaldehyde concentration determination (Nash, 1953) was used. In summary, the Nash reagent $(2 \mathrm{ml})$ and the analyte $(0.1 \mathrm{ml})$ were incubated at $60^{\circ} \mathrm{C}$ for $5 \mathrm{~min}$ and then diluted to a total volume of $10 \mathrm{ml}$ with water. The absorbance of the diluted reaction mixture was read at $412 \mathrm{~nm}$. A calibration curve was prepared using a standard solution of $1 \mathrm{M}$ formaldehyde (produced by the hydrolysis of the more stable polymer paraformaldehyde in a sealed bottle for $12 \mathrm{~h}$ at $100^{\circ} \mathrm{C}$ ).

Enzyme assays. The amounts of formate and acetate produced in enzyme assays were determined by HPLC analysis. A $50 \mu \mathrm{l}$ sample was taken from an enzyme reaction mixture and diluted with $50 \mu \mathrm{l}$ concentrated phosphoric acid. This sample was centrifuged at $16500 \mathrm{~g}$ for $5 \mathrm{~min}$ prior to a $25 \mu \mathrm{l}$ aliquot being loaded onto a HiChrom Licrosphere HPLC column equilibrated with an aqueous solution of $0.01 \mathrm{M}$ octylamine adjusted to $\mathrm{pH} \mathrm{6.6} \mathrm{with} \mathrm{phosphoric} \mathrm{acid.} \mathrm{The} \mathrm{sample} \mathrm{was}$

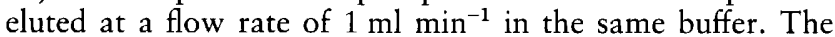
concentrations of formate and acetaldehyde in enzyme assay mixtures were determined by comparing their absorbance at $210 \mathrm{~nm}$ with the absorbances of known standard concentrations.

Formaldehyde oxidation rates in crude soluble extracts were determined at $45^{\circ} \mathrm{C}$ by measuring the formation of NADH from $\mathrm{NAD}^{+}$spectrophotometrically at $340 \mathrm{~nm}$. A typical reaction mixture contained $4 \mathrm{mg}$ protein, $1 \mathrm{mg}$ heat-treated soluble extract (see below), $3 \mathrm{mM} \mathrm{KCN}, 2 \mathrm{mM} \mathrm{NAD}^{+}, 2 \mathrm{mM}$ formaldehyde and $25 \mathrm{mM}$ phosphate buffer, $\mathrm{pH} 7 \cdot 2$, made to a final volume of $1 \mathrm{ml}$ with water. After preincubation at $45^{\circ} \mathrm{C}$ for $3 \mathrm{~min}$, the reaction was started by the addition of formaldehyde. When the activity of purified enzyme was being assessed, the $3 \mathrm{mM} \mathrm{KCN}$ was omitted from the assay mixture.

Activity of the modifin was determined by its ability to restore the formaldehyde oxidation activity of partially purified FDH. A typical reaction mixture contained $1 \mathrm{mg}$ crude $\mathrm{FDH}, 4 \mathrm{mg}$ protein sample containing modifin, $3 \mathrm{mM} \mathrm{KCN}, 2 \mathrm{mM} \mathrm{NAD}^{+}$ and $25 \mathrm{mM}$ phosphate buffer, $\mathrm{pH} 7 \cdot 2$, made to a final volume of $1 \mathrm{ml}$ with water. After preincubation as above, the reaction was initiated by the addition of $2 \mathrm{mM}$ formaldehyde. The rate of NADH formation was measured at $340 \mathrm{~nm}$ over a $5 \mathrm{~min}$ period.

Protein determination. Total protein concentrations of FDHcontaining solutions were determined using the Bio-Rad protein determination, with bovine serum albumin (BSA) as standard.

The concentration of purified modifin was determined spectrophotometrically at $205 \mathrm{~nm}$ (Stoscheck, 1987). Modifin solutions were diluted until their concentration was approximately $1-10 \mathrm{mg} \mathrm{ml}^{-1}$ and the absorbance read at $205 \mathrm{~nm}$.

Determination of bound NAD ${ }^{+}$. $\mathrm{NAD}^{+}$bound to FDH was identified by ion-exchange chromatography. FDH (4 mg) was treated with $6 \mathrm{M}$ urea in $0 \cdot 1 \mathrm{M}$ Tris $/ \mathrm{HCl}, \mathrm{pH} 7 \cdot 5$. The sample was boiled for $2 \mathrm{~min}$ and allowed to cool. A $1.0 \mathrm{ml}$ aliquot of the sample was then desalted on a Pharmacia Fast Desalt column at a flow rate of $2 \mathrm{ml} \mathrm{min} \mathrm{m}^{-1}$ against $10 \mathrm{mM}$ Tris $/ \mathrm{HCl}$, $\mathrm{pH} 8.0$, containing $6 \mathrm{M}$ urea. The salt fraction $(2 \mathrm{ml})$ was loaded onto a Pharmacia Mono Q (HR5/5) column equilibrated with the desalting buffer. The sample was eluted in a linear gradient of $0-1.0 \mathrm{M} \mathrm{KCl}$ in 15 column volumes (CV) at a flow rate of $0.5 \mathrm{ml} \mathrm{min}^{-1}$. Standard $\mathrm{NAD}^{+}$and NADH were also urea-treated and served as standards for the identification of $\mathrm{NAD}^{+}$in the test sample.

Growth of organism. M. capsulatus (Bath) was grown in a continuous culture vessel $(2 \mathrm{l})$ under oxygen-limiting conditions on nitrate mineral salt medium buffered with $\mathrm{HCl}$ at pH 7.2 (Dalton \& Whittenbury, 1976). Cells were grown at $45^{\circ} \mathrm{C}$ at a dilution rate of $0.024 \mathrm{~h}^{-1}$ with methane $(25 \% \mathrm{v} / \mathrm{v}$ in air) as the sole carbon and energy source. Bacteria were harvested from a $20 \mathrm{l}$ overflow vessel by centrifugation at $10000 \mathrm{~g}$ for $10 \mathrm{~min}$. The resulting cell pellet was washed by resuspending in $100 \mathrm{ml} 20 \mathrm{mM}$ phosphate buffer, $\mathrm{pH} \mathrm{7.2.} \mathrm{The}$ resuspended cells were centrifuged at $10000 \mathrm{~g}$ for $10 \mathrm{~min}$, the supernatant removed and the cell paste resuspended in $20 \mathrm{ml}$ of the same buffer. The cells were stored drop-frozen in liquid nitrogen at $-80^{\circ} \mathrm{C}$.

Protein purification. Cell extract containing both FDH and the modifin was prepared by passing defrosted cell paste through a Constant Systems (Holly Farm Business Park, Honiley, UK) cell disrupter at $146 \mathrm{MPa}$ and centrifugation at $68500 \mathrm{~g}$ for $1.5 \mathrm{~h}$. The supernatant was retained as the crude extract. Protein purification was performed using either a Pharmacia FPLC system or a Pharmacia BioPilot system.

\section{FDH purification procedure}

Step $1.30 \%(\mathrm{w} / \mathrm{v})$ ammonium sulphate was added to crude extract and left to stand on ice for $30 \mathrm{~min}$. Precipitated material was removed by centrifugation at $48500 \mathrm{~g}$. Ammonium sulphate was increased in the supernatant to $55 \%$ $(\mathrm{w} / \mathrm{v})$ and the precipitate again removed by centrifugation. The pellet was redissolved in a minimum volume of $25 \mathrm{mM}$ Tris/ $\mathrm{HCl}, \mathrm{pH} 7 \cdot 2$, containing $50 \mathrm{mM} \mathrm{KCl}$.

Step 2. The FDH active solution from Step 1 was loaded onto a custom-packed Pharmacia Superdex 200 pg (XK 50/1000) gel filtration column, previously equilibrated with $2 \mathrm{CV}$ 
$25 \mathrm{mM}$ Tris/ $\mathrm{HCl}, \mathrm{pH} 7 \cdot 2$, containing $50 \mathrm{mM} \mathrm{KCl}$ and $1 \mathrm{mM}$ benzamidine. The protein was eluted at a flow rate of $0.75 \mathrm{CV}$ $\mathrm{h}^{-1}$ in the same buffer and $4 \mathrm{ml}$ fractions were collected. Fractions showing FDH activity were pooled and concentrated in an Amicon ultrafiltration unit over a membrane with a $30 \mathrm{kDa}$ exclusion limit at $4{ }^{\circ} \mathrm{C}$.

Step 3 . The concentrated active protein from the gel filtration column was loaded onto a Pharmacia (HR 26/10) QSepharose anion-exchange column equilibrated with $25 \mathrm{mM}$ Tris/HCl, pH 7.2. After sample loading, the column was washed with 1 vol. equilibration buffer and then the concentration of $\mathrm{KCl}$ was increased to $0.3 \mathrm{M}$ in the same buffer, over $0.25 \mathrm{CV}$. The FDH protein was eluted in a linear gradient of $0.3-0.5 \mathrm{M} \mathrm{KCl}$ in the same buffer, over $3 \mathrm{CV}$. The column was regenerated by increasing the $\mathrm{KCl}$ concentration to $1 \mathrm{M}$ for $2 \mathrm{CV}$. Collected fractions were tested for formaldehyde oxidation activity. Active fractions were pooled and concentrated over a $30 \mathrm{kDa}$ exclusion limit at $4^{\circ} \mathrm{C}$.

Step 4. The active FDH material from Step 3 was loaded onto a Pharmacia Superdex 75 (HR 10/30) column equilibrated with $25 \mathrm{mM}$ Tris/ $\mathrm{HCl}$ buffer, $\mathrm{pH} 7 \cdot 2$, containing $100 \mathrm{mM}$ $\mathrm{KCl}$. Protein was eluted at a flow rate of $0.75 \mathrm{CV} \mathrm{h}^{-1}$. Fractions were collected and those which demonstrated FDH activity were pooled, drop-frozen in liquid nitrogen and stored at $-80{ }^{\circ} \mathrm{C}$.

\section{Preparation of heat-treated soluble extract and purification of the modifin}

Step 1. Crude extract was heated to $70^{\circ} \mathrm{C}$ for $12 \mathrm{~min}$. The precipitated material was removed by centrifugation at $10000 \mathrm{~g}$ for $20 \mathrm{~min}$. The supernatant was used as heat-treated soluble extract (HTSE).

Step 2. The HTSE solution was loaded onto a Pharmacia QSepharose (HR 26/10) anion-exchange column equilibrated with $20 \mathrm{mM}$ HEPES buffer, $\mathrm{pH} 7 \cdot 2$, containing $1 \mathrm{mM}$ benzamidine. After sample loading the column was washed for $2 \mathrm{CV}$ with equilibration buffer at a flow rate of $6 \mathrm{CV} \mathrm{h}^{-1}$. The sample was eluted from the column using a linear gradient of $0-1.0 \mathrm{M} \mathrm{KCl}$ in $5 \mathrm{CV}$ equilibration buffer. Fractions were collected and those showing modifin activity were pooled and concentrated in an Amicon ultrafiltration unit over a membrane with an exclusion limit of $3 \mathrm{kDa}$.

Step 3. The concentrated protein from Step 2 was loaded onto a Pharmacia Superdex $75 \mathrm{pg}$ (HR 26/60) column. The fractions were eluted with $20 \mathrm{mM}$ HEPES buffer, $\mathrm{pH} 7 \cdot 2$, containing $1 \mathrm{mM}$ benzamidine at a flow rate of $0.75 \mathrm{CV} \mathrm{h}$. Collected fractions were assayed for modifin activity. Those exhibiting activity were pooled and concentrated over a membrane with an exclusion limit of $3 \mathrm{kDa}$ ultrafiltration membrane. The concentrated material was sterile filtered through a $0.2 \mu \mathrm{m}$ Whatman PVDF filter and stored at room temperature.

UV-visible spectra of proteins. All proteins were diluted in $25 \mathrm{mM}$ phosphate buffer prior to measuring the absorbance over a wavelength range $220-800 \mathrm{~nm}$.

Molecular mass determinations. The molecular mass of FDH was estimated by SDS-PAGE using a $15 \%(\mathrm{w} / \mathrm{v})$ gel system with low-molecular-mass protein standard markers (Novex). Accurate molecular mass measurements of FDH and modifin were made using electrospray ionization mass spectrometry (ESI-MS) on a Quattro II tandem mass spectrometer (Micromass, Altrincham, UK). ESI-MS experiments were carried out in the nebulizer-assisted electrospray mode. The potential of the electrospray needle was set at $3.5 \mathrm{kV}$ and the extraction cone voltage was set at $50 \mathrm{~V}$. FDH was diluted to $40 \mathrm{pmol} \mathrm{ml}^{-1}$ in Tris buffer, $\mathrm{pH} 7 \cdot 2$, containing $5 \%(\mathrm{v} / \mathrm{v})$ acetic acid. Aliquots of $10 \mu \mathrm{l}$ were introduced into the source at a flow rate of $5 \mu \mathrm{l} \mathrm{min}{ }^{-1}$. Mass spectra were acquired over the range $\mathrm{m} / z$ 600-1700. Calibration was carried out using a solution of horse heart myoglobin.

$\mathrm{N}$-terminal sequence analysis. Protein samples for N-terminal sequence analysis were prepared as described by Packman (1993). Protein bands visualized on PVDF membranes were excised and sent for N-terminal sequence analysis at the University of Southampton Protein Sequencing Unit.

\section{RESULTS}

\section{Purification of protein components}

Attempts to purify FDH by the procedure previously reported by Stirling \& Dalton (1978) resulted in heavy contamination by the hydroxylase component of the soluble methane monooxygenase (sMMO). Table 1 summarizes the procedure developed in this study which gave a reliable purification of FDH from $M$. capsulatus (Bath) soluble extract without sMMO contamination (which was removed by the Q-Sepharose chromatographic step). During purification of $\mathrm{FDH}$, stabilization of formaldehyde oxidation activity proved difficult. Attempts to stabilize activity by inclusion of protease inhibitors such as benzamidine, or glycols such as mannitol or glycerol, had no effect on formaldehyde oxidation activity. Although a large amount of FDH activity was lost during the S200 gel filtration chromatography step, by using this step to remove the ammonium sulphate from the active fractions, purification time and the loss of enzyme activity were minimized.

A small $(10 \mathrm{kDa})$ protein was identified by SDS-PAGE (Fig. 1, lanes D and E) in the last two stages of the FDH purification scheme. This contaminating molecule was removed by the final gel filtration step and corresponded to a loss in background formaldehyde oxidation activity. When this small protein was collected from the $S 75$ gel filtration column and added back to FDH preparations, the background rate of formaldehyde oxidation activity was restored. It was concluded that the small protein identified was the modifin which copurified with the FDH.

Purification of the modifin has not been reported previously and Table 2 summarizes the procedure developed. Heat treatment of the soluble extract was required for the activity of the modifin to be discernible in crude soluble extract. Therefore no data are given for the activity of modifin in crude extract. This heat treatment was a useful initial step in the purification, removing approximately $75 \%$ of contaminating soluble protein, whilst attempts to purify the modifin without heat treatment were unsuccessful. It is possible that the modifin may be associated with another protein which is liberated upon heat treatment. An increase in the yield of modifin was also observed during the purification. It is possible that the modifin was removed from a component which interfered with the activity of the modifin or FDH. The purified material was active for 
Table 1. Purification of FDH

\begin{tabular}{|c|c|c|c|c|c|c|}
\hline Purification step & $\begin{array}{l}\text { Volume } \\
\qquad(\mathrm{ml})\end{array}$ & $\begin{array}{c}\text { Total } \\
\text { protein } \\
(\mathrm{mg})\end{array}$ & $\begin{array}{c}\text { Total } \\
\text { activity }(\mathbf{U})\end{array}$ & $\begin{array}{c}\text { Specific } \\
\text { activity } \\
(\mu \mathrm{mol} \\
\left.\mathrm{min}^{-1} \mathrm{mg}^{-1}\right)\end{array}$ & $\begin{array}{l}\text { Yield } \\
(\%)\end{array}$ & $\begin{array}{l}\text { Purification } \\
\text { factor }\end{array}$ \\
\hline Crude extract & 190 & 9500 & 36100 & 4 & 100 & 1 \\
\hline $\begin{array}{l}\text { Ammonium sulphate } \\
\text { precipitation }\end{array}$ & 60 & 3720 & 33500 & $9 \cdot 3$ & 92 & $2 \cdot 3$ \\
\hline Gel filtration chromatography & 40 & 134 & 4600 & 34 & $12 \cdot 7$ & $8 \cdot 5$ \\
\hline Ion-exchange Q-Sepharose & 24 & $16 \cdot 8$ & 3900 & 232 & $10 \cdot 8$ & 58 \\
\hline Superdex 75 & 10 & $16 \cdot 4$ & 3850 & 234 & $10 \cdot 7$ & $58 \cdot 5$ \\
\hline
\end{tabular}

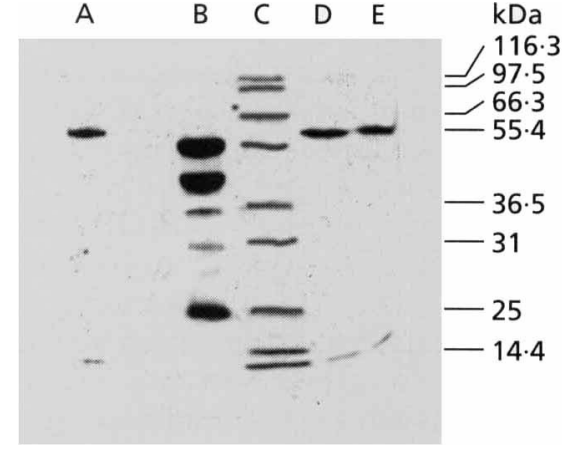

Fig. 1. SDS-PAGE ( $15 \%$ acrylamide) of purified FDH. Lane $A$, $10 \mu \mathrm{g}$ purified $\mathrm{FDH}$; lane $\mathrm{B}, 50 \mu \mathrm{g}$ purified hydroxylase of sMMO; lane C, Novex wide-range protein standards (116.3 kDa $\beta$-galactosidase, $97.5 \mathrm{kDa}$ phosphorylase $b, 66.3 \mathrm{kDa}$ bovine serum albumin, $55.4 \mathrm{kDa}$ glutamate dehydrogenase, $36.5 \mathrm{kDa}$ lactate dehydrogenase, $31 \mathrm{kDa}$ carbonic anhydrase, $25 \mathrm{kDa}$ soyabean trypsin inhibitor, $14.4 \mathrm{kDa}$ lysozyme and $6.5 \mathrm{kDa}$ aprotinin); lanes D and $E, 10 \mu \mathrm{g}$ and $20 \mu \mathrm{g}$ purified FDH.

over 3 months when stored in $20 \mathrm{mM}$ HEPES, $\mathrm{pH} 7 \cdot 2$, at room temperature.

\section{Determination of molecular mass, subunit composition and $\mathrm{N}$-terminal sequence of FDH and modifin}

FDH. The subunit molecular mass of FDH was determined as $60 \mathrm{kDa}$ by SDS-PAGE (Fig. 1) and as $63615 \mathrm{Da}$ by ESI-MS. The molecular mass of the native
FDH complex was determined as $250 \mathrm{kDa}$ by gel filtration (data not shown) using a Pharmacia Superdex 200 gel filtration column. We assume therefore that $\mathrm{FDH}$ exists as a tetramer of $63 \mathrm{kDa}$ subunits; this contrasts with the data published by Stirling \& Dalton (1978), who reported that FDH was a dimer of $57 \mathrm{kDa}$ subunits.

Modifin. The molecular mass of the modifin, as determined by ESI-MS, gave two species of molecular mass 8211 and $16421 \mathrm{Da}$, indicating either that the protein sample was heterogeneous or that the modifin existed as a dimer. The native molecular mass of the modifin was determined by gel filtration chromatography using a Pharmacia (HR10/30) S12 column. Pure modifin eluted as two species corresponding to approximately 10 and $20 \mathrm{kDa}$ molecular mass (data not shown). This confirms that the two species identified by ESI-MS are both modifin and it is concluded from these data that the modifin exists as both a monomer and a dimer, of molecular mass $8211 \mathrm{Da}$ and $16421 \mathrm{Da}$, respectively.

Purified samples of FDH and modifin were blotted onto PVDF membranes and their $\mathrm{N}$-terminal sequences determined. Fig. 2 shows the sequence data generated from the two samples. These data were used to search the EMBL and SWISS-PROT databases for similar sequences using the EBI BLAST alignment program. No matching sequences were identified for either sequence. Comparison of the $\mathrm{N}$-terminal sequence for $\mathrm{FDH}$ with published sequences of other FDH enzymes also showed no similarity with FDH enzymes which have been previously isolated from methylotrophic organisms. Searching the databases for proteins with similar amino

Table 2. Purification of the modifin

\begin{tabular}{|lcccccc|}
\hline Purification step & $\begin{array}{c}\text { Volume } \\
(\mathbf{m l})\end{array}$ & $\begin{array}{c}\text { Total } \\
\text { protein } \\
(\mathbf{m g})\end{array}$ & $\begin{array}{c}\text { Total } \\
\text { activity }(\mathrm{U})\end{array}$ & $\begin{array}{c}\text { Specific } \\
\text { activity } \\
(\mu \mathrm{mol} \\
\left.\mathbf{m i n}^{-1} \mathbf{m g}^{-1}\right)\end{array}$ & $\begin{array}{c}\text { Yield } \\
(\%)\end{array}$ & $\begin{array}{c}\text { Purification } \\
\text { factor }\end{array}$ \\
\hline Heat treatment & 75 & 2250 & $49 \cdot 5$ & 22 & 100 & 1 \\
Ion-exchange Q-Sepharose & 220 & 2046 & $94 \cdot 6$ & 46 & 190 & $2 \cdot 0$ \\
Gel filtration S75 & 60 & 24 & $72 \cdot 6$ & 3025 & 145 & 138 \\
\hline
\end{tabular}




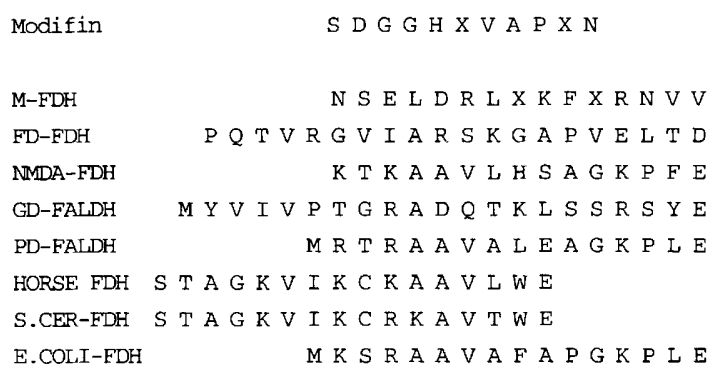

Fig. 2. N-terminal sequences of FDH and the modifin. Amino acids are symbolized by their single-letter code and $\mathrm{X}$ indicates an unidentified residue. FD-FDH, factordependent FDH from $A$. methanolica (van Ophem et al., 1992); NMDA-FDH, 4-nitroso$\mathrm{N}, \mathrm{N}$-dimethylaniline-dependent $\mathrm{FDH}$ from Rhodococcus rhodochrous (van Ophem \& Duine, 1994); GD-FALDH, glutathionedependent FDH from Methylobacter marinus (Ras et al., 1995); PD-FALDH, glutathione-dependent FDH from Paracoccus denitrificans (Ras et al., 1995); HORSE FDH, glutathione-dependent FDH from horse tissue (Jornvall et al., 1987); S.CER-FDH, glutathione-dependent FDH from Saccharomyces cerevisiae (Jornvall et al., 1987), E.COLI-FDH, glutathionedependent FDH from Escherichia coli (Gutheil et al., 1992).

Table 3. Substrate specificity of FDH in the presence and absence of the modifin

$100 \%$ activity is equivalent to $240 \mathrm{nmol} \mathrm{NADH}$ formed min $^{-1}$ from $0.6 \mu \mathrm{M}$ FDH in the presence of $20 \mu \mathrm{M}$ modifin. Each substrate tested was added to the reaction mixture to a final concentration of $2 \mathrm{mM}$.

\begin{tabular}{|lcc|}
\hline \multirow{2}{*}{ Substrate } & \multicolumn{2}{c|}{ Activity (\%) } \\
\cline { 2 - 3 } & With modifin & Without modifin \\
\hline Formaldehyde & 100 & 0 \\
Acetaldehyde & 0 & 57 \\
Propanal & 0 & 37 \\
Butanal & 0 & 8 \\
Pentanal & 0 & $<1$ \\
Methanol & 0 & 18 \\
Ethanol & 0 & 50 \\
Propanol & 0 & 21 \\
Butanol & 0 & 10 \\
Benzaldehyde & 0 & 0 \\
Glyceraldehyde & 0 & 0 \\
\hline
\end{tabular}

acid sequences and molecular masses also generated no matching proteins.

\section{Substrate specificity of FDH and kinetics of formaldehyde/acetaldehyde oxidation}

It was reported previously that $\mathrm{FDH}$, in the presence of a heat-stable cofactor, was able to catalyse the oxidation of formaldehyde and a range of complex aldehydes (Stirling \& Dalton, 1978). The activity of FDH in the absence of the heat-stable cofactor was not determined at that time. In this study the active component of the heat-stable extract (the modifin) was used to further characterize the substrate specificity of FDH. Table 3 shows that FDH is able to oxidize a range of aldehydes and alcohols in the absence of the modifin. Furthermore,

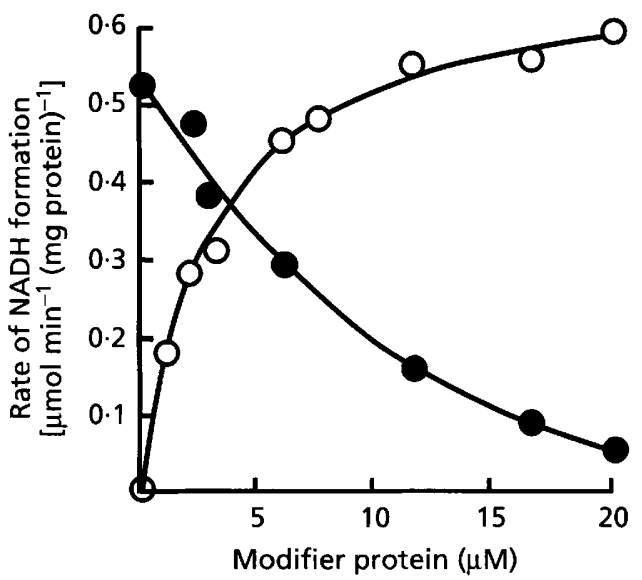

Fig. 3. Effect of increasing concentrations of modifin on the rates of oxidation of formaldehyde $(0)$ and acetaldehyde $(O)$. Enzyme reactions were performed as described in Methods.

formaldehyde was only oxidized by FDH when the modifin was present. This demonstrates that the modifin is acting as a powerful control protein to regulate formaldehyde oxidation. This is graphically demonstrated in Fig. 3, where the rate of formaldehyde and acetaldehyde oxidation are displayed as a function of the modifin concentration. Increasing the concentration of the modifin inhibits acetaldehyde oxidation with a concomitant increase in the rate of formaldehyde oxidation. This figure also shows that for maximum formaldehyde oxidation activity the $\mathrm{FDH}$ : modifin ratio should be $1: 4$ or greater.

The ability of FDH to oxidize alcohols in the absence of modifin (Table 3) has also been observed for FDH enzymes purified from Amycolatopsis methanolica and Hyphomicrobium X (van Ophem et al., 1992; Poels \& Duine, 1989). These enzymes were able to catalyse the oxidation of alcohols and aldehydes, but required the presence of reduced glutathione for the catalysis of 


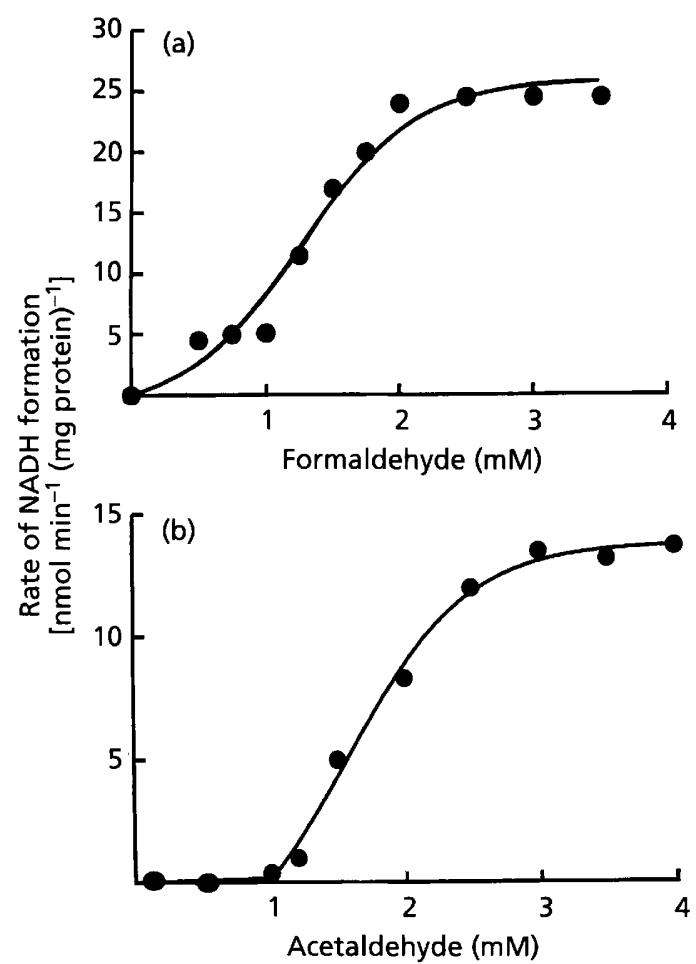

Fig. 4. Oxidation of (a) formaldehyde and (b) acetaldehyde in the presence and absence of modifin. Enzyme reactions were performed as described in Methods, i.e. $4 \mathrm{mg}$ purified FDH, $2 \mathrm{mM} \mathrm{NAD}+2 \mathrm{mM}$ substrate and $25 \mathrm{mM}$ phosphate buffer, $\mathrm{pH}$ 7.2 , made to a final volume of $1 \mathrm{ml}$ with water. When formaldehyde was the substrate $1 \mathrm{mg}$ modifin was added to the reaction mixture and when acetaldehyde was the substrate the modifin was omitted. NADH formation was determined at $340 \mathrm{~nm}$ over $5 \mathrm{~min}$ and the rate of formation determined from the spectrophotometer.

formaldehyde oxidation. The effect of reduced glutathione on the rate of formaldehyde oxidation by FDH isolated from $M$. capsulatus (Bath) was therefore investigated. Glutathione concentrations up to $2 \mathrm{M}$ were added to the FDH reaction mixture in the absence of modifin but in no instance was formaldehyde oxidation detected.

van Ophem et al. (1992) demonstrated that high concentrations of methanol had a similar effect as glutathione in FDH enzymes isolated from A. methanolica. Methanol was therefore added to the M. capsulatus FDH reaction mixture (up to a final concentration of $2 \mathrm{M}$ ) in the absence of modifin and formate production determined. No restoration of formaldehyde oxidation activity to FDH was observed.

The stoichiometry for the catalysis of formaldehyde and acetaldehyde oxidation in the presence and absence of modifin was investigated. A known amount of formaldehyde $(100 \mathrm{nmol})$ and $\mathrm{NAD}^{+}(2 \mathrm{mmol})$ was added to the $\mathrm{FDH} /$ modifin reaction mixture and the concentrations of formate and NADH formed were determined after $30 \mathrm{~min}$. This experiment was repeated using FDH in the absence of the modifin with $100 \mathrm{nmol}$ acet-

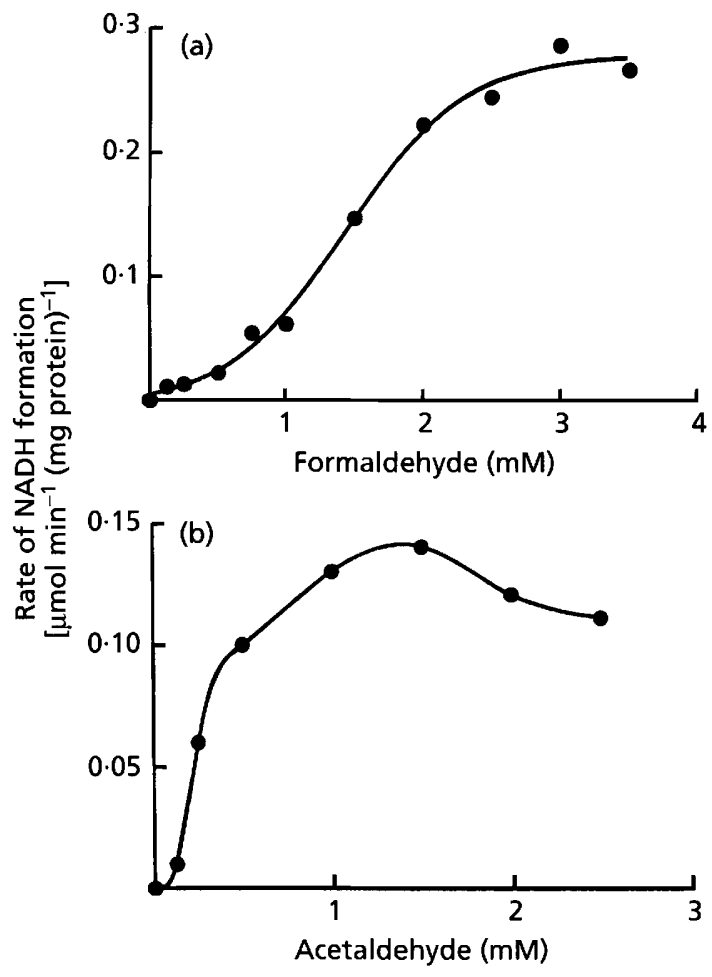

Fig. 5. Effect of removing bound substrate on the rate of (a) formaldehyde oxidation and (b) acetaldehyde oxidation by FDH. Enzyme reactions were performed as for Fig. 4.

aldehyde as substrate and determining the amounts of acetate and NADH formed after $30 \mathrm{~min}$. The oxidation of $100 \mathrm{nmol}$ formaldehyde produced $94 \mathrm{nmol}$ formate and $116 \mathrm{nmol} \mathrm{NADH}$ whilst the oxidation of $100 \mathrm{nmol}$ acetaldehyde, in the absence of modifin, produced $107 \mathrm{nmol}$ acetate and $119 \mathrm{nmol} \mathrm{NADH}$. In both cases there is a stoichiometric relationship between substrate consumption and product formation, indicating a dehydrogenase activity. If FDH could perform a dismutase reaction, then the ratio of substrate to product would not be that observed, as the products of the dismutase reaction would be formate and methanol; no methanol was detected in this reaction.

Investigation of the kinetic constants for formaldehyde and acetaldehyde oxidation showed another important property of the modifin. Formaldehyde oxidation, in the presence of the modifin, showed a sigmoidal increase in the rate of $\mathrm{NADH}$ formation with increasing formaldehyde concentrations (Fig. 4a). However, a minimum concentration of acetaldehyde was required before substrate oxidation would occur. Acetaldehyde oxidation followed standard Michaelis-Menten kinetics thereafter (Fig. 4b). No oxidation of acetaldehyde was observed at substrate concentrations less than $1.5 \mathrm{mM}$, suggesting that there may be an inhibitor of acetaldehyde oxidation bound to the purified FDH.

To determine the nature of the molecule bound to FDH the enzyme was allowed to turn over in the presence of 


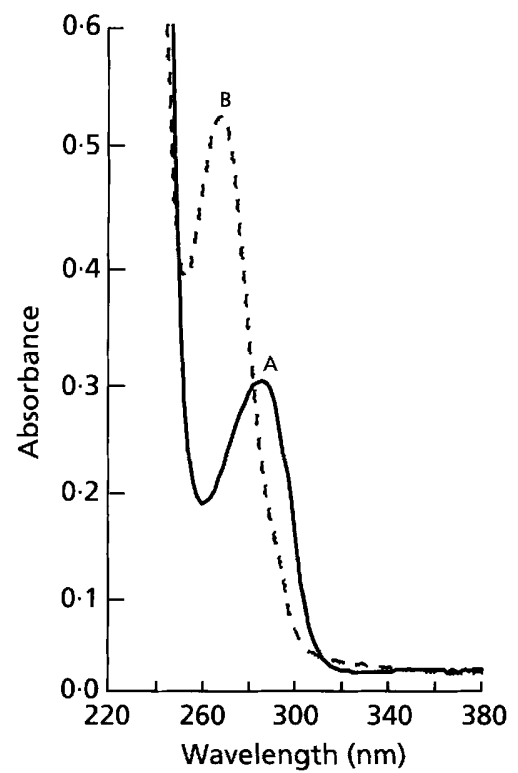

Fig. 6. Absorbance spectrum of FDH pre- and post-turnover. $\mathrm{FDH}$ was diluted to $1 \mathrm{mg} \mathrm{ml}^{-1}$ in $25 \mathrm{mM}$ phosphate buffer, $\mathrm{pH}$ $7 \cdot 2$, and the UV-visible spectra taken over the wavelength range 200-340 nm. A, FDH purified as described in Methods, absorbance maximum $278 \mathrm{~nm}$; $\mathrm{B}, \mathrm{FDH}$ repurifed after reacting with excess $\mathrm{NAD}^{+}$, absorbance maximum $254 \mathrm{~nm}$.

modifin and excess $\mathrm{NAD}^{+}(2 \mathrm{mmol})$. In the experiment, $2 \cdot 1 \mu \mathrm{mol} \mathrm{NADH}$ was produced when $2 \cdot 0 \mu \mathrm{mol} \mathrm{FDH}$ was added to the reaction mixture. These data show that the amount of NADH produced was equal to the amount of FDH present in the reaction mixture. The formation of NADH only occurred in the presence of modifin, indicating that the inhibitor of acetaldehyde oxidation was an oxidizable substrate, most probably formaldehyde.

The FDH from the turnover experiment above was repurified using a Superdex 75 (HR 10/30) (Pharmacia) equilibrated with $25 \mathrm{mM}$ Tris $/ \mathrm{HCl}, \mathrm{pH} 7 \cdot 2$, and $100 \mathrm{mM} \mathrm{NaCl}$. The repurified FDH was then used to determine the rates of formaldehyde and acetaldehyde oxidation in the presence and absence of modifin respectively (Fig. 5). After the turnover of FDH no substantial difference in the kinetics of formaldehyde oxidation was observed (Fig. 5a). However, oxidation of acetaldehyde was detectable at low substrate concentrations (Fig. 5b); a double reciprocal plot of these data showed a negative co-operativity effect.

Concurrent with the removal of the bound substrate was an alteration in the absorbance spectrum of FDH (Fig. 6). It would appear from the shift in the absorbance maximum that $\mathrm{NAD}^{+}$was bound to $\mathrm{FDH}$. The presence of $\mathrm{NAD}^{+}$was confirmed by ion-exchange chromatography (data not shown) as described in Methods. The amount of bound $\mathrm{NAD}^{+}$was determined from its absorbance maximum at $254 \mathrm{~nm}$, indicating $8 \mu \mathrm{mol}$ $\mathrm{NAD}^{+}$per $2 \mu \mathrm{mol} F D H$. This demonstrated that one $\mathrm{NAD}^{+}$molecule bound to each subunit of $\mathrm{FDH}$.

\section{DISCUSSION}

Data presented in this paper have identified a lowmolecular-mass protein (modifin) which confers formaldehyde-oxidizing activity in vitro on a general alcohol/ aldehyde dehydrogenase that otherwise shows no activity towards formaldehyde.

FDH enzymes purified from methylotrophic bacteria are usually dimers or trimers (van Ophem et al., 1992; Eggeling \& Sahm, 1985; Attwood et al., 1992; Ando et al., 1979), unlike the FDH isolated here, which appears to be a tetramer of $63 \mathrm{kDa}$ subunits. The increased size of this FDH enzyme may be due to its requirement for a regulatory component, the modifin. Many FDH enzymes isolated from methylotrophic bacteria only oxidize formaldehyde in the presence of glutathione (GSH), and N-terminal sequence analysis of these enzymes has shown they are similar to type III alcohol dehydrogenase enzymes (van Ophem et al., 1992). These FDH enzymes have been termed GSH-dependent formaldehyde dehydrogenases, gFDHs (van Ophem et al., 1992; Eggeling \& Sahm, 1984, 1985). Although the molecular mass, N-terminal sequence (Fig. 2) and cosubstrate requirement of FDH from $M$. capsulatus are different from those of gFDH enzymes, FDH can oxidize alcohols in the absence of the modifin, suggesting that it may be an alcohol dehydrogenase which oxidizes formaldehyde. Attempts to replace the modifin with glutathione proved unsuccessful, indicating that FDH purified from $M$. capsulatus (Bath) oxidized formaldehyde by a different mechanism from that proposed for gFDH enzymes. It is probable that a modifin-induced conformational change of FDH allows formaldehyde oxidation to occur and that the modifin does not complex with formaldehyde. This differs from gFDH enzymes, which oxidize the more stable $S$-(hydroxymethyl)glutathione, formed spontaneously in solution from formaldehyde and GSH (Holmquist \& Vallee, 1991).

The substrate specificity in the presence and absence of modifin was determined for a range of simple aldehydes and alcohols. The data showed that formaldehyde oxidation, catalysed by $\mathrm{FDH}$, only occurred in the presence of the modifin whereas the oxidation of higher aldehydes and alcohols was only detected in the absence of the modifin. Thus we believe that the modifin may alter substrate specificity of the dehydrogenase in a similar way to that in which $\alpha$-lactalbumin changes the substrate specificity of $\gamma$-galactosyltransferase, causing it to use glucose, rather than $\mathrm{N}$-acetylglucosamine, as a substrate in lactating mammary glands (Hill \& Brew, 1975).

During purification of the modifin, its yield, after the anion-exchange step, increased to $190 \%$, suggesting that an inhibitor of formaldehyde oxidation was being removed at this stage. Stirling \& Dalton (1978) reported an increase in the yield of the FDH component (they did not purify the modifin) which they attributed to the separation of FDH from NADH oxidase, which interfered with the FDH assay. Although we did not identify 
the inhibitory component in the present investigation, it is tempting to speculate that this factor may play a role in regulating the activity of the modifin itself (an antimodifin?)

Purified FDH was shown to have one formaldehyde molecule tightly bound to the enzyme; this may be important for stabilization of FDH in vivo or it could act as a regulator of activity by preventing the enzyme from oxidizing other substrates such as alcohols or higher aldehydes. Although we have not identified this molecule unequivocally, we believe it is likely to be formaldehyde, based on the observation that it can only be removed following turnover of the enzyme by addition of the modifin and $\mathrm{NAD}^{+}$. Once this substrate is removed, bound $\mathrm{NAD}^{+}$can be detected on FDH. The association of $\mathrm{NAD}^{+}$with $\mathrm{FDH}$ does not appear to be as strong as that of $\mathrm{NAD}^{+}$in methanol dehydrogenase isolated from Bacillus methanolicus (Arfman et al., 1997). In the case of methanol dehydrogenase, an activator protein is believed to facilitate the cycling of the permanently bound $\mathrm{NAD}^{+}$between oxidized and reduced states (Arfman et al., 1997). If $\mathrm{NAD}^{+}$was bound to $\mathrm{FDH}$ in this manner, an absorbance maximum of the purified enzyme at $265 \mathrm{~nm}$ should be visible, but no such absorbance was detected (Fig. 6). It is assumed that formaldehyde binds preferentially before $\mathrm{NAD}^{+}$, or that the modifin is required for $\mathrm{NAD}^{+}$binding.

The observed co-operativity and high affinity of formaldehyde binding in vitro suggests a detoxification role for FDH in preventing the accumulation of formaldehyde within the cell, in a manner similar to that proposed for other FDH enzymes (Fernandez et al., 1995; Harms et al., 1996). Such a 'safety valve' system is extremely important in methylotrophic bacteria since the formation of formaldehyde is an integral step in the growth of these organisms (Anthony, 1982). Without a method for the removal of any freely available formaldehyde, cell death would rapidly ensue.

There are three potential enzymes responsible for formaldehyde oxidation in M. capsulatus (Bath): methanol dehydrogenase (MDH) (Long \& Anthony, 1991), FDH (Stirling \& Dalton, 1978) and a cytochromedependent FDH (Hay, 1990). Both the cytochromedependent $\mathrm{FDH}$ and the $\mathrm{MDH}$ are not reactive with NAD/NADH. Thus the function of the FDH and modifin characterized here may be to serve not only as a 'safety valve' but also to supply NADH. As NADH is required for the hydroxylation of methane by sMMO (Colby \& Dalton, 1978) without an $\mathrm{NAD}^{+}$-linked FDH the cells would almost certainly be NADH-limited during growth (Anthony, 1982). An earlier proposition that tetrahydrofolate-linked enzymes may be involved in formaldehyde oxidation by methylotrophs (Attwood \& Quayle, 1984) has recently been verified by Chistoserdova et al. (1998) for Methylobacterium extorquens AM1, but these enzymes have not been identified in $M$. capsulatus (Bath) as yet.

In conclusion, it is proposed that the modifin is a novel control protein which regulates formaldehyde oxidation in M. capsulatus (Bath) in vitro. Data presented in this paper demonstrate the ability of the modifin to alter both the kinetics and the substrate specificity of alcohol/ aldehyde dehydrogenase. It is possible that the physiological function of the modifin is both to reduce formaldehyde concentrations and to generate NADH for methane hydroxylation by sMMO. The precise signals which stimulate expression and activity of the modifin are unknown but the data presented indicate that both high formaldehyde and $\mathrm{NAD}^{+}$concentrations are probable signals. The identification of mutants or deletion of the modifin gene will allow its impact on the physiology of $M$. capsulatus (Bath) to be dissected and verify the intracellular signals required to stimulate activity.

\section{ACKNOWLEDGEMENTS}

We thank Dr P. Wilkins for technical and intellectual support and Dayo Adeosun and Armelle Buzy for help with the MS analysis during this study. This work was supported by the BBSRC through a studentship to S.T.

\section{REFERENCES}

Ando, M., Yoshimoto, T., Ogushi, S., Rikitake, K., Shibata, S. \& Tsuru, D. (1979). Formaldehyde dehydrogenase from Pseudomonas putida. J Biochem 85, 1165-1172.

Anthony, C. (1982). The Biochemistry of Methylotrophs. London: Academic Press.

Arfman, N., Hektor, H. J., Bystrykh, L. V., Govorukhina, N. I., Dijkhuizen, L. \& Frank, J. (1997). Properties of an NAD(H)containing methanol dehydrogenase and its activator protein from Bacillus methanolicus. Eur J Biochem 244, 426-433.

Attwood, M. \& Quayle, J. R. (1984). Formaldehyde as a central intermediary metabolite of methylotrophic metabolism. In Microbial Growth on $C_{1}$ Compounds, pp. 315-323. Edited by R. L. Crawford \& R. S. Hanson. Washington, DC: American Society for Microbiology.

Attwood, M., Arfman, N., Westhuis, R. \& Dijkhuizen, L. (1992). Purification and characterisation of an $\mathrm{NAD}^{+}$-linked formaldehyde dehydrogenase from the facultative RuMP cycle methylotroph Arthrobacter P1. Antonie Leeuwenhoek 62, 201-207.

Boulton, C. A. \& Large, P. J. (1977). Synthesis of certain assimilatory and dissimilatory enzymes during bacterial adaptation to growth on trimethylamine. J Gen Microbiol 101, 151-156.

Chistoserdova, L., Vorholt, J. A., Thauer, R. K. \& Lidstrom, M. E. (1998). $C_{1}$ transfer enzymes and coenzymes linking methylotrophic bacteria and methanogenic Archaea. Science 281, 99-102.

Colby, J. \& Dalton, H. (1978). Resolution of the methane monooxygenase of Methylococcus capsulatus (Bath) into three components. Purification and properties of component C, a flavoprotein. Biochem J 171, 461-468.

Dalton, H. \& Whittenbury, R. (1976). The acetylene reduction technique as an assay for nitrogenase activity in the methane oxidizing bacterium Methylococcus capsulatus strain Bath. Arch Microbiol 109, 147-151.

Eggeling, L. \& Sahm, H. (1984). An unusual formaldehyde oxidising system in Rhodococcus erythropolis grown on compounds containing methyl groups. FEMS Microbiol Lett 25, 253-257.

Eggeling, L. \& Sahm, H. (1985). The formaldehyde dehydrogenase 
of Rhodococcus erythropolis, a trimeric enzyme requiring a cofactor and active with alcohols. Eur J Biochem 150, 129-134.

Fernandez, M. R., Biosca, J. A., Norin, A., Jornvall, H. \& Pares, X. (1995). Class III alcohol dehydrogenase from Saccharomyces cerevisiae: structural and enzymatic features differ toward the human/mammalian forms in a manner consistent with functional needs in formaldehyde detoxification FEBS Lett 370, 23-26.

Gutheil, W. G., Holmquist, B. \& Vallee, B. L. (1992). Purification, characterization and partial sequence of the glutathione dependent formaldehyde dehydrogenase from Escherichia coli: a Class III alcohol dehydrogenase. Biochemistry 31, 475-481.

Hampton, D. \& Zatman, L. J. (1973). The metabolism of tetramethylammonium chloride by bacterium $5 \mathrm{H} 2$. Biochem Soc Trans 1, 667-668.

Harms, N., Ras, J., Reijnders, W. N. M., van Spanning, R. J. M. \& Stouthamer, A. H. (1996). S-Formylglutathione hydrolase of Paracoccus denitrificans is homologous to human esterase D: a universal pathway for formaldehyde detoxification? J Bacteriol 178, 6296-6299.

Harrington, A. A. \& Kallio, R. E. (1960). Oxidation of methanol and formaldehyde by Pseudomonas methanica. Can J Microbiol 6, 1-7.

Hay, S. (1990). Regulation of $C_{1}$ metabolism in Methylococcus capsulatus (Bath). PhD thesis, University of Warwick.

Hill, R. L. \& Brew, K. (1975). Lactose synthetase. Adv Enzymol Relat Areas Mol Biol 43, 411-490.

Holmquist, B. \& Vallee, B. L. (1991). Human class III alcohol and glutathione dependent formaldehyde dehydrogenase are the same. Biochem Biophys Res Commun 178, 1371-1377.

Johnson, P. A. \& Quayle, J. R. (1964). Microbial growth on $C_{1}$ compounds. Oxidation of methanol, formaldehyde and formate by methanol-grown Pseudomonas AM1. Biochem J 93, 281-290.

Jornvall, H., Persson, B. \& Jeffery, J. (1987). Characteristics of alcohol/polyol dehydrogenase. Eur J Biochem 167, 195-201.

Large, E. \& Quayle, J. R. (1963). Enzyme activities in extracts of Pseudomonas AM1. Biochem J 87, 386-396.

Long, A. R. \& Anthony, C. (1991). The periplasmic modifier of methanol dehydrogenase in the methylotrophs Methylophilus methylotrophus and Paracoccus denitrificans. J Gen Microbiol 137, 2353-2360.

Nash, T. (1953). The colorimetric estimation of formaldehyde by means of the Hantzsch reaction. Biochem J 55, 416-421.

van Ophem, P. W. \& Duine, J. A. (1994). NAD- and co-substrate (GSH or factor)-dependent formaldehyde dehydrogenase from methylotrophic micro-organisms act as a class III alcohol dehydrogenase. FEMS Microbiol Lett 116, 87-94.

van Ophem, P. W., van Beeuman, J. \& Duine, J. A. (1992). NADlinked, factor-dependent formaldehyde dehydrogenase or trimeric, zinc-containing, long-chain alcohol dehydrogenase from Amycolatopsis methanolica. Eur J Biochem 206, 511-518.

Packman, L. C. (1993). Protein chemical methods for molecular biologists. Methods Mol Cell Biol 4, 89-198.

Patel, R. N. \& Hoare, D. S. (1971). Physiological studies of methane and methanol-oxidizing bacteria : oxidation of $\mathrm{C}_{1}$ compounds by Methylococcus capsulatus. J Bacteriol 107, 187-192.

Poels, P. A. \& Duine, J. A. (1989). NAD-linked, GSH- and factorindependent aldehyde dehydrogenase of methylotrophic bacterium, Hyphomicrobium X. Arch Biochem Biophys 271, 240-245.

Ras, J., van Ophem, P. W., Reijnders, W. N. M., van Spanning, R. J. M., Duine, J. A., Stouthamer, A. H. \& Harms, N. (1995). Isolation, sequencing and mutagenesis of the gene encoding NAD and glutathione dependent formaldehyde (GD-FALDH) from Paracoccus denitrificans in which GD-FALDH is essential for methylotrophic growth. J Bacteriol 177, 247-251.

Stirling, D. I. \& Dalton, H. (1978). Purification and properties of an $\mathrm{NAD}(\mathrm{P})^{+}$-linked formaldehyde dehydrogenase from Metbylococcus capsulatus (Bath). J Gen Microbiol 107, 19-29.

Stoscheck, C. M. (1987). Protein assay at nanogram levels. Anal Biochem 160, 301-305.

Received 7 August 1998; revised 21 September 1998; accepted 24 September 1998. 